\title{
A new pragmatic design for dose escalation in phase 1 clinical trials using an adaptive continual reassessment method
}

\author{
Bernard North ${ }^{1,3}$, Hemant Mahendrakumar Kocher ${ }^{2 *}$ and Peter Sasieni ${ }^{1,4}$
}

\begin{abstract}
Background: A key challenge in phase I trials is maintaining rapid escalation in order to avoid exposing too many patients to sub-therapeutic doses, while preserving safety by limiting the frequency of toxic events. Traditional rulebased designs require temporarily stopping recruitment whilst waiting to see whether enrolled patients develop toxicity. This can be both inefficient and introduces logistic challenges to recruitment in the clinic. We describe a novel two-stage dose assignment procedure designed for a phase I clinical trial (STARPAC), where a good estimation of prior was possible.
\end{abstract}

Methods: The STARPAC design uses rule-based design until the first patient has a dose limiting toxicity (DLT) and then switches to a modified CRM, with rules to handle patient recruitment during follow-up of earlier patients. STARPAC design is compared via simulations with the TITE-CRM and $3+3$ methods in various toxicity estimate (T1-5), rate of recruitment (R1-2), and DLT events timing (DT1-4), scenarios using several metrics: accuracy of maximum tolerated dose (MTD), numbers of DLTs, number of patients enrolled and those missed; duration of trial; and proportion of patients treated at the therapeutic dose or MTD.

Results: The simulations suggest that STARPAC design performed well in MTD estimation and in treating patients at the highest possible therapeutic levels. STARPAC and TITE-CRM were comparable in the number of patients required and DLTs incurred. The $3+3$ design often had fewer patients and DLTs although this is due to its low escalation rate leading to poor MTD estimation. For the numbers of declined patients and MTD estimation $3+3$ is uniformly worse, with STARPAC being better in those metrics for high toxicity scenarios and TITE-CRM better with low toxicity. In situations including doses with toxicities both above and below 30\%, the STARPAC design outperformed TITE-CRM with respect to every metric.

Conclusion: When considering doses with toxicities both above and below the target of $30 \%$ toxicities, the two-stage STARPAC dose escalation design provides a more efficient phase I trial design than either the traditional $3+3$ or the TITE-CRM design. Trialists should model various designs via simulation to adopt the most efficient design for their clinical scenario.

Trial registration: Clinical Trials NCT03307148 (11 October 2017).

Keywords: Adaptive design, Bayesian adaptive, Simulation, $3+3$ design, Maximal tolerated dose, Dose-finding, CRM, Model-based design, Rule-based design

\footnotetext{
* Correspondence: h.kocher@qmul.ac.uk

${ }^{2}$ Centre for Tumour Biology and Experimental Cancer Medicine, Barts Cancer

Institute- a CRUK Centre of Excellence, Queen Mary University London,

London EC1M 6BQ, UK

Full list of author information is available at the end of the article
}

(c) The Author(s). 2019 Open Access This article is distributed under the terms of the Creative Commons Attribution 4.0 International License (http://creativecommons.org/licenses/by/4.0/), which permits unrestricted use, distribution, and reproduction in any medium, provided you give appropriate credit to the original author(s) and the source, provide a link to the Creative Commons license, and indicate if changes were made. The Creative Commons Public Domain Dedication waiver (http://creativecommons.org/publicdomain/zero/1.0/) applies to the data made available in this article, unless otherwise stated. 


\section{Background}

Phase I clinical trials are an essential early-stage investigation in the development of anti-cancer and other therapeutic drugs. The main goal of these studies is to identify the appropriate dose for new drugs or drug combinations for phase II trials, often called the recommended phase 2 dose (RP2D). These studies typically involve a small number of patients. A key principle for dose escalation in phase I trials is maintaining rapid dose-escalation in order to avoid exposing too many patients to sub-therapeutic doses while preserving safety by limiting the frequency of toxic events (dose limiting toxicities or DLTs). The maximum tolerated dose (MTD) is estimated limiting the probability of a DLT to a particular level, the target toxicity level (TTL), which is often set at $30 \%$. Dose escalation methods for phase I cancer clinical trials fall into two broad classes: the traditional and often used rule-based, or "up and down", designs, which include the traditional $3+3$ design [1,2] and its variations; and relatively recent, model-based designs such as the continual reassessment method (CRM) [3].

The most commonly employed rule-based design is the $3+3$ design. It sequentially enrols cohorts of three patients; the first cohort is treated at a starting dose that is considered to be safe based on extrapolation from animal toxicological data or prior experience in other disease conditions, and the subsequent cohorts are treated at increasing dose levels that have been fixed in advance. The $3+3$ is conservative with respect to the number of toxicities which occur, because the dose escalation is performed with caution, but it can potentially lead to a large number of patients needed to estimate the MTD, especially if the true MTD is located in the upper range of the doses tested. This method has been criticized for assigning low, possibly sub-therapeutic, doses to a high proportion of patients, often only making use of information given by the last three or six patients enrolled; thereby providing an inefficient estimation of the MTD and inflexibility in that the method is tailored to a target toxicity level of around $30 \%$.

An alternative to the rule-based methods for finding the MTD is to use a model-based approach that assumes there is a monotone relationship between the dose and the probability of a DLT. The most commonly applied model-based approach is the CRM and its variants. The CRM pre-specifies a dose-toxicity curve (DTC) as well as the TTL. Prior estimates of the probability of a DLT at each dose level are provided based on clinical experience. The DTC is updated with accumulating toxicity data from the trial. New patients are given the MTD derived from the updated DTC.

The CRM method in its original form treated patients individually with the initial patient dosed at the MTD suggested by the (possibly inaccurate) prior DTC, allowed dose escalations of more than one level (dose skipping), and required a fixed number of patients (usually around 20). This caused some criticism both on the grounds of excess toxicity exposure and the length of the study given toxicity data from previous patients may take time to occur. Modified designs treat the initial patient at a low level and do not allow dose-skipping. They may also treat patients in cohorts of more than one, and include early stopping rules to limit study duration [4]. Another suggestion to limit toxicity is the escalation with overdose control method [5].

A further class of models designed to address the issue of limited information in the early stage of a CRM are the two-stage designs $[6,7]$ whereby patients are initially treated according to some rule-based design with a transition to the CRM approach often on occurrence of the first DLT.

\section{Relative performance of the CRM and $3+3$ method}

Both the $3+3$ and the CRM method with its variants have advantages and disadvantages depending on the toxicity profile of the drug, the number of dose levels, the DLT required, and the accuracy of the prior estimate of the CRM dose-toxicity curve [8,9]. Although ruledbased designs, compared with model-based designs, tend to have lower probability of finding the true MTD and to have more patients treated at sub-MTD doses with potentially less therapeutic value, they are likely to have fewer toxicities and can, sometimes, require fewer patients. These four metrics: MTD accuracy, patients dosed at MTD, low toxicity and economy of patient numbers are important in comparing the performance of alternative phase 1 designs. Van Brummelen et al., 2016 reported that $(n=11)$ model-based trials were shorter, requiring fewer patients, incurred a lower percentage of DLTs and treated fewer patients at potentially sub-therapeutic levels compared with $(n=161)$ rulebased trials.

Recent (UK) Medical Research Council (MRC) [10], Committee for Medicinal Products for Human Use (CHMP), (CHMP 2006) and FDA (FDA 2011) guidance recommends that alternative to the $3+3$ designs should be considered. Despite these design modifications and recommendations, the CRM and its variants have not been widely adopted with up to $94 \%$ of studies $(n=172)$ following a rule-based design. (van Brummelen et al., 2016).

Love (2017) found that the most prominent barriers to implementation of a model-based design (e.g. CRM) were lack of suitable training, chief investigators' preference for rule-based designs (e.g., $3+3$ ), a mistaken belief in regulatory preference for rule-based designs and limited resources for study design before funding especially 
when DLT may occur in a delayed fashion (up to few weeks after initial administration) or is cumulative after repeated administration of a drug.

\section{Accrual given incomplete DLT observation}

A challenge of using both rule-based and model-based methods is that a toxicity/DLT may not be observed for some time after a patient is recruited. In cancer trials it is common to wish to consider DLT's observed during the first cycle of treatment (usually 14-28 days). Even when using cohorts of three patients at the same dose, this can result in patients being recruited while previous patients have only partial follow-up and therefore, with incomplete toxicity responses. This is particularly a problem early in a trial when the next patient could be recruited and require a dose recommendation, when no previous patients have completed their first cycle to estimate full toxicity. There have been several attempts to address this both in the context of rule-based and model-based studies. An alternative rule-based design, [11], the accelerated titration design, treats one patient per dose level until a patient experiences a DLT at which point the traditional $3+3$ method is employed. Another rule-based approach, the rolling six design [12], allows for accrual of two to six patients on the same dose which is determined by the number of patients currently enrolled and evaluable, the number experiencing doselimiting toxicity (DLT), and the number still at risk of developing a DLT. Within the CRM context one of the modifications previously suggested [4] was to recruit patients in cohorts rather than singly to increase accrual. A modification to the CRM process was proposed [13] called the time-to-event continual reassessment method (TITE-CRM), that allows patients to be entered in a staggered fashion enrolling new patients while existing patients have an incomplete observation by incorporating the time to the event (the event being a DLT) or the partial follow-up without DLT for each patient. This method can be an efficient method of allowing the advantages of a CRM design to be used with partial followup. However, early in the study, unless overdose control is employed or dose-skipping prevented, this method can lead to increased DLTs [14].

In this article we propose an alternative to TITE-CRM (in order to overcome its limitations) for the STARPAC trial by using a hybrid two-stage dose escalation with an initial stage of accelerated dose escalation until the occurrence of a DLT at which point an amended CRM is employed. We then compare the STARPAC design proposal with standard $3+3$ design, and TITE-CRM using $\sim 1000$ simulations per scenario to evaluate the key metrics of these designs: patients required and skipped (patient burden), DLTs encountered (toxicity), study length (economy), MTD determination (accuracy), patients dosed at MTD (therapeutic utility).

\section{Methods \\ The STARPAC trial}

STARPAC is a Phase 1 trial of repurposing all transretinoic acid (ATRA) as a stromal targeting agent for pancreatic cancer alongside gemcitabine and nabPaclitaxel. STARPAC patients have histologically proven pancreatic ductal adenocarcinoma (PDAC) which is locally advanced or metastatic disease which is measurable according to the Response Evaluation Criteria in Solid Tumours (RECIST v1.1). Pancreatic cancer is the fourthhighest cancer killer worldwide ( 310,000 patients), responsible for $6 \%$ of cancer deaths (overall median survival $\sim 3$ months). One of the characteristics of pancreatic cancer is its intense desmoplastic stroma, which can account for up to $70 \%$ of the tumour volume and actively participates in tumour initiation, progression, metastases and the response to therapy [15]. The formation of stroma is driven by pancreatic stellate cells (PSCs) as they change from a quiescent, vitamin A storing phenotype to an activated myofibroblast-like cell. Normalising the tumour stroma by reprogramming PSCs to their quiescent phenotype by all-trans retinoic acid (ATRA) [16, 17], and thereby restoring a more physiological secretome, is an attractive approach to be explored with this trial. The combination of gemcitabinenab-Paclitaxel is licenced for treatment of pancreatic cancer with well-known toxicity profile [18]. ATRA is also a well-established drug with more than four decades of clinical experience for other cancers [19-22], and its analogues, such as 13-cis retinoic acid (13cisRA)) have been used in context of pancreatic cancer [23-25]. However, the combination of these three drugs has never been used in pancreatic cancer, and hence the phase I clinical trial. The toxicities are well-known and are hypothesised for the purposed of design to be additive and non-synergistic based on the knowledge of mode of action. Therefore, five dose levels were considered, to ensure that no patients are treated at sup-optimal cytotoxic chemotherapy level. Lowest combination of cytotoxic chemotherapy was chosen at $80 \%$ because that was median dosing intensity in phase III clinical trial [26]. Hence we have designed the STARPAC trial with five dose levels, D1-D5, of Gemcitabine, Nab-Paclitaxel and ATRA identifies the MTD (maximum tolerated dose, Table 1).

\section{The STARPAC design and rules}

We implemented a two-stage dose selection in order to balance prevention of excessive toxicity with the objective of maintaining rapid dose escalation when justified as described before [27], where rule-based design (Stage 1) was 
Table 1 Dose Levels of STARPAC clinical trial

\begin{tabular}{lllllll}
\hline Dose level & Gemcitabine & \multicolumn{4}{l}{ Nab-Paclitaxel } & ATRA \\
\hline D1 & $80 \%$ & $800 \mathrm{mg} / \mathrm{m}^{2}$ & $80 \%$ & $100 \mathrm{mg} / \mathrm{m}^{2}$ & $33 \%$ & $15 \mathrm{mg} / \mathrm{m}^{2}$ \\
D2 & $80 \%$ & $800 \mathrm{mg} / \mathrm{m}^{2}$ & $80 \%$ & $100 \mathrm{mg} / \mathrm{m}^{2}$ & $66 \%$ & $30 \mathrm{mg} / \mathrm{m}^{2}$ \\
D3 & $80 \%$ & $800 \mathrm{mg} / \mathrm{m}^{2}$ & $80 \%$ & $100 \mathrm{mg} / \mathrm{m}^{2}$ & $100 \%$ & $45 \mathrm{mg} / \mathrm{m}^{2}$ \\
D4 & $100 \%$ & $1000 \mathrm{mg} / \mathrm{m}^{2}$ & $80 \%$ & $100 \mathrm{mg} / \mathrm{m}^{2}$ & $100 \%$ & $45 \mathrm{mg} / \mathrm{m}^{2}$ \\
D5 & $100 \%$ & $1000 \mathrm{mg} / \mathrm{m}^{2}$ & $100 \%$ & $125 \mathrm{mg} / \mathrm{m}^{2}$ & $100 \%$ & $45 \mathrm{mg} / \mathrm{m}^{2}$ \\
\hline
\end{tabular}

used with a switch to a model-based dose escalation algorithm (Stage 2) upon occurrence of the first DLT. The first three patients are assigned to dose level D2 unless one of those three patients incurs a DLT when the switch to the CRM-based Stage 2 will occur. The dose selection design is implemented using the $\mathrm{R}$ programming language with the CRM component using the bcrm package [28] (Additional file 1).

Since DLTs usually manifest after two weeks [26], STARPAC Stage 1 uses two key rules to determine dose escalation for patients, when no DLT occurs:

- If a patient has received two-weeks of treatment on the current dose level, the next patient to be recruited will be allocated to the next higher dose level.

- If no patient has received two-weeks of treatment on the current dose level, the next patient to be recruited will be dosed on the same dose level.

On occurrence of the first DLT, Stage 2 uses a CRM model using data from patients who have had a DLT or more than three weeks on study treatment without a DLT. The CRM uses Bayesian methodology based on a power function dose toxicity curve, using physician experience to estimate the probability of toxicity occurring at each dose level D1-D5 as $10,15,20,25$ and $30 \%$ respectively [24-26]. We use the hyperbolic tangent parameter has the suggested initial lognormal prior distribution with mean zero and variance $1.34^{2}$ [29]. As patient toxicity data is accumulated alongside their assigned doses, this is input to the modified CRM, which will then recommend a dose level for the next patient employing a dose-skipping restriction [30].

The study stopping rule was defined when 6 patients are recruited to the same dose throughout either stage or when 24 patients are recruited in total. At that point a CRM analysis will be performed on the data when all patients have completed their first cycle ( 28 days). The final MTD will be defined as the highest dose level of ATRA and Gemcitabine / Nab-Paclitaxel for which the CRM estimated probability of a patient experiencing a DLT is closest to $30 \%$. The design also allows us to switch from Stage 2 back to Stage 1 in the event that a possible DLT is later determined not to have been a DLT.

As a further safety measure, we also ensure that a maximum of three patients are recruited (on the same dose) in any two-week period. For example, if first patient three are recruited by week 4 (on say dose level D2), and next two patients are recruited in week 5 (on D3), then if patient 6 arrives in week 5 they can be recruited (on D3) provided there have been no DLTs. We will allow a third patient in a 2 -week period to wait up to seven days before start of treatment in order for this condition not to be violated. If more than seven days is required before a patient becomes eligible then the patient is not recruited to the trial and is allocated to standard care.

The STARPAC design assigns first patient to dose level D2. If no DLT has been observed, next patient is assigned to either the same dose as the previous patient, if no patient on that dose has received at least 2 weeks of treatment; or, the next dose if at least one patient has already received 2 weeks of treatment at that dose. However, once a DLT has been observed, the next dose is assigned using a model-based CRM taking into account all DLTs and all patients who have had at least 3 weeks of treatment without a DLT. We use a power function dose toxicity curve and do not allow dose-skipping - if the dose is to be increased it will only do so by one level. We will stop recruitment when 6 patients have recruited to the same dose or when the 24th patient is recruited. Once all patients have completed 28 days of followup, the MTD is selected as that with a posterior probability of a DLT that is closest to the TTL. This is illustrated in Fig. 1.

\section{Simulations}

The properties of the STARPAC design were assessed with simulation by the $\mathrm{R}$ programming language [31] using the $\mathrm{bcrm}$ function (Additional file 1). Hypothetical data was simulated with plausible various scenarios, based on clinical experience [18] (Table 2). The STARPAC design was compared to both the TITE-CRM procedure and the classic $3+3$ procedure.

\section{Suppositions applied to TITE-CRM}

TITE-CRM was applied to the simulations using the logistic form for the DTC and starting with the first 3 patients at D2 unless a DLT occurs. The titecrm function of the $d f$ crm $R$ package [32] was used for assigning doses to the simulated patients. For the TITE-CRM procedure the safety measure of a maximum of three patients recruited in any two-week period was also applied. 


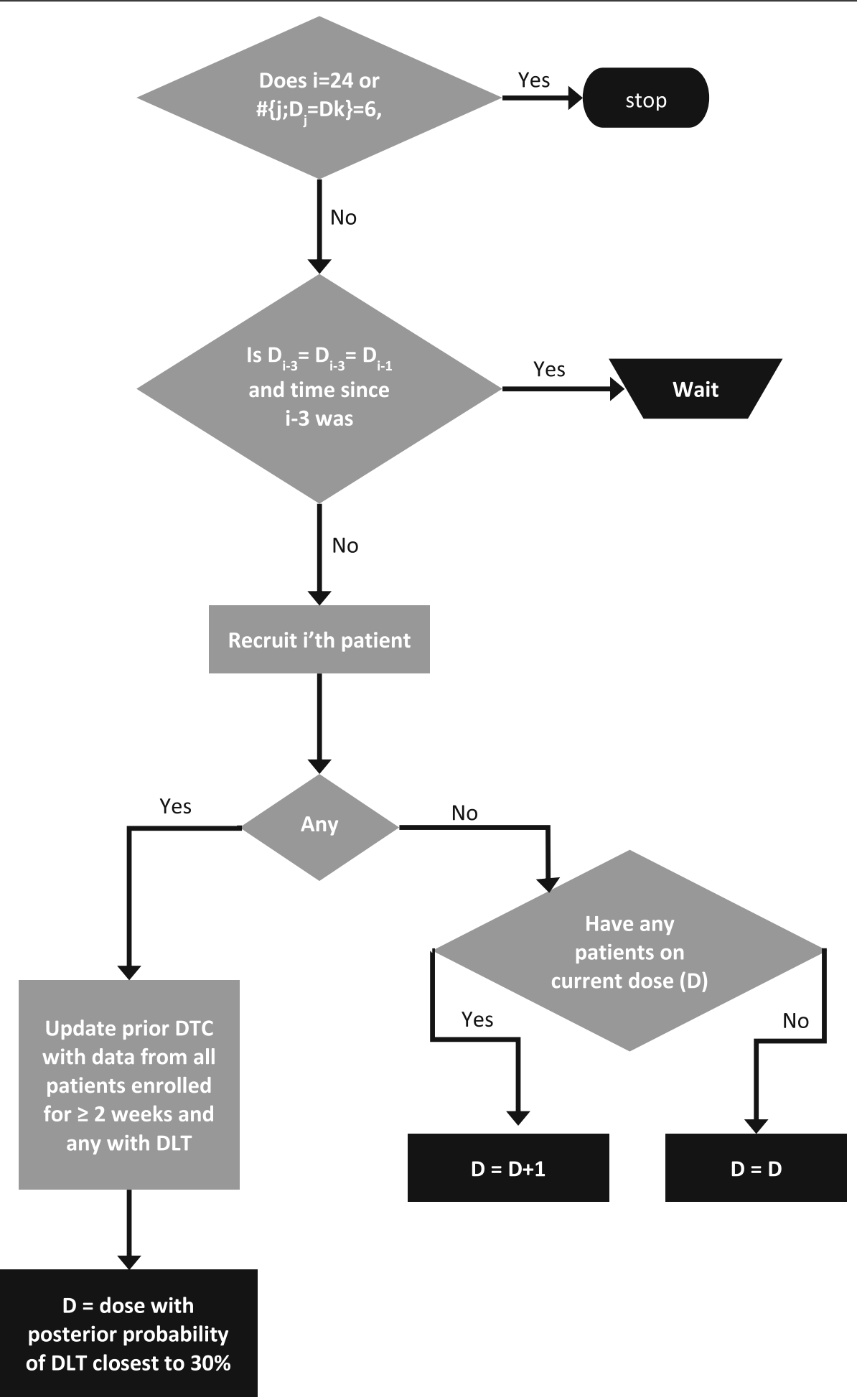

Fig. 1 Flowchart of STARPAC design

\section{Suppositions for $3+3$ design}

The $3+3$ method was also applied starting at D2, with excessive toxicity at a dose leading to dose de-escalation. If the lower dose has been evaluated before, it is declared to be the (estimated) MTD. However, if the lower dose has not been evaluated then three patients are recruited. If all doses are declared too toxic by $3+3$, then no MTD is declared. For the $3+3$ design, 
Table 2 Scenarios for simulation

\begin{tabular}{lllllll}
\hline \multirow{2}{*}{$\begin{array}{l}\text { Toxicity } \\
\text { scenario }\end{array}$} & Type of scenario & \multicolumn{7}{l}{ Dose Levels } \\
\cline { 3 - 7 } & & D1 & D2 & D3 & D4 & D5 \\
\hline T1 & Linear, very high & 10 & 20 & $\mathbf{3 0}$ & 40 & 50 \\
T2 & Linear, high & 10 & 20 & 25 & $\mathbf{3 0}$ & 40 \\
T3 & Linear, anticipated & 10 & 15 & 20 & 25 & $\mathbf{3 0}$ \\
T4 & Linear, low & 5 & 10 & 12 & 15 & 20 \\
T5 & Non-linear, variable & 5 & 15 & $\mathbf{3 0}$ & 50 & 70 \\
\hline
\end{tabular}

1. Rates of recruitment scenarios (R): patients recruited randomly, with two (Poisson process) arrival rates considered:

a. R1: routine average arrival 1 patient per week and

b. R2: accelerated average arrival rate 1.5 patients per week.

2 Toxicity occurrence scenarios $(\mathrm{T})$

3. The DLT times (for those with a DLT) were simulated using 4 timing (DT) scenarios:

a. DT1: uniformly between 8 and 21 days after recruitment: most plausible based on clinical experience [16]

b. DT2: uniformly between 11 and 28 days after recruitment

c. DT3: at either 11 or 21 days with probabilities of 25 and $75 \%$

d. DT4: at either 11 or 21 days with probabilities 30 and $70 \%$.

Bold typeface signifies acceptable DLT to declare MTD.

presenting patients were not recruited if the three patients currently being treated had not yet provided a toxicity result enabling the dose level of the next three patients to be determined. A toxicity result is available when the current 3 patients complete their cycle without any DLTs (at which point the next three can be recruited at a higher dose level) or with 1 DLT (at which point the next three can be recruited at the same dose level), or when a second DLT occurs (at which point the next three can be recruited at a lower dose level) or if for a second set of three patients (after a previous single DLT) when a single DLT occurs (at which point the next three can be recruited at a lower dose level). Any patients presenting while the next dose level is undetermined are unable to be recruited.

1000 datasets were simulated using each of the three designs and for each of the forty (toxicity (T) and DLT timing (DT)) scenarios using the different patient arrival rates $(\mathrm{R})$.

These in silico simulations did not require ethical approval, as no humans or animals were used. STARPAC study was approved by South Central - Berkshire Research Ethics Committee (15/SC/0548), but is not part of the manuscript.

\section{Results}

\section{Simulation results}

Summary of performance based on simulations for STARPAC, TITE-CRM and $3+3$ designs is presented in terms of: patients required and skipped (not-recruited due to insufficient information to determine next dosing level: patient burden), DLTs encountered (toxicity), study length (economy), MTD determination (accuracy), patients dosed at MTD (therapeutic utility) in Table 3.
We also report the proportion of times each dose level is selected as MTD and the proportion of patients treated at each dose (Additional file 2).

In Table 3 data are summarised for the three designs in each of the five toxicity (T) scenarios. Values in Table 3 are for DLT timing-scenario DT1. Results for the study length and the numbers of patients skipped are presented separately depending on the recruitment rate. For all other results, the value in Table 3 is for R1 (one patient per week). Below each value in Table 3 is the range of that parameter across the four DLT timing scenarios (DT1-DT4) and (except for study length and patients skipped) the two recruitment rates. It is interesting to note that the ranges are narrow compared to the differences between designs and toxicity scenarios, suggesting that DLT timing scenarios has limited impact on any of the designs, an important consideration for future designs.

\section{Accuracy to determine MTD}

The classic, rule-based $3+3$ design never accurately estimates the correct MTD. For the scenarios including doses with greater than $30 \%$ toxicity (T1 and T2), STARPAC design is more likely to select the correct MTD than the other two designs, but all fair poorly. For those with the maximal dose included to be less than or equal to $30 \%$ (T3 and T4), TITE-CRM is more likely to pick the correct MTD, than STARPAC design. In these scenarios (T3 and T4), STARPAC is much more likely to pick the correct MTD than $3+3$. We note that the likelihood of identifying the MTD with any of these designs is highly variable depending on the underlying toxicities of the doses considered. For example, in scenario T2, the MTD is only correctly identified less than $20 \%$ of the time (even by the best design). For scenario T4 in which the maximal dose has toxicity of just $20 \%$, TITE-CRM correctly chooses that does up to $90 \%$ of the time, and STARPAC over $70 \%$. In the highly variable, non-linear scenario, STARPAC design outperforms the other two designs.

\section{Toxicity (DLT frequency)}

None of the designs has more than average six patients with DLTs in any of the scenarios studied, and mostly the mean is 3-4 DLTs per trial. For four of the five toxicity rate scenarios, $3+3$ has the fewest patients and the fewest DLTs, but, as noted, it is also least likely to select the target dose. We must note that a design that stops after treating three patients at the lowest dose will always recruit the fewest and have the fewest DLTs, but it does not help one find the MTD. TITE-CRM design has the most DLTs in all scenario compared to other design, except for T4 scenario where STARPAC design fairs poorly. 
Table 3 Results of simulations

\begin{tabular}{|c|c|c|c|c|c|c|c|c|}
\hline Design & toxicity & patients & DLTS & $\begin{array}{l}\text { study length } \\
(1.0 / \mathrm{wk})\end{array}$ & $\begin{array}{l}\text { number skipped } \\
\text { (1.0/wk) }\end{array}$ & $\begin{array}{l}\text { study length } \\
(1.5 / \mathrm{wk})\end{array}$ & $\begin{array}{l}\text { number skipped } \\
(1.5 / \mathrm{wk})\end{array}$ & MTD \\
\hline STARPAC & $\mathrm{T} 1$ & $\begin{array}{l}12.2 \\
(12.2,12.7)\end{array}$ & $\begin{array}{l}3.28 \\
(3.20,3.54)\end{array}$ & $\begin{array}{l}15.8 \\
(15.8,16.1)\end{array}$ & $\begin{array}{l}3.47 \\
(3.47,3.76)\end{array}$ & $\begin{array}{l}13.2 \\
(13.0,13.6)\end{array}$ & $\begin{array}{l}7.32 \\
(7.32,7.67)\end{array}$ & $\begin{array}{l}0.342 \\
(0.317,0.363)\end{array}$ \\
\hline TITE-CRM & $\mathrm{T} 1$ & $\begin{array}{l}14.5 \\
(14.5,15.3)\end{array}$ & $\begin{array}{l}4.23 \\
(4.23,4.66)\end{array}$ & $\begin{array}{l}19.1 \\
(19.1,19.9)\end{array}$ & $\begin{array}{l}4.27 \\
(4.27,4.57)\end{array}$ & $\begin{array}{l}16.2 \\
(15.9,16.3)\end{array}$ & $\begin{array}{l}9.07 \\
(9.07,9.41)\end{array}$ & $\begin{array}{l}0.217 \\
(0.162,0.217)\end{array}$ \\
\hline $3+3$ & $\mathrm{~T} 1$ & $\begin{array}{l}10.2 \\
(10.1,10.4)\end{array}$ & $\begin{array}{l}2.64 \\
(2.62,2.71)\end{array}$ & $\begin{array}{l}20.9 \\
(20.9,22.2)\end{array}$ & $\begin{array}{l}9.90 \\
(9.90,10.28)\end{array}$ & $\begin{array}{l}17.9 \\
(17.9,19.0)\end{array}$ & $\begin{array}{l}14.44 \\
(14.41,14.95)\end{array}$ & $\begin{array}{l}0.234 \\
(0.234,0.260)\end{array}$ \\
\hline STARPAC & $\mathrm{T} 2$ & $\begin{array}{l}12.5 \\
(12.4,13.2)\end{array}$ & $\begin{array}{l}3.01 \\
(2.97,3.30)\end{array}$ & $\begin{array}{l}16.2 \\
(16.2,16.5)\end{array}$ & $\begin{array}{l}3.70 \\
(3.67,3.75)\end{array}$ & $\begin{array}{l}13.2 \\
(13.2,14.1)\end{array}$ & $\begin{array}{l}7.57 \\
(7.50,8.09)\end{array}$ & $\begin{array}{l}0.163 \\
(0.117,0.174)\end{array}$ \\
\hline TITE-CRM & $\mathrm{T} 2$ & $\begin{array}{l}14.0 \\
(13.8,14.3)\end{array}$ & $\begin{array}{l}3.66 \\
(3.59,3.81)\end{array}$ & $\begin{array}{l}18.3 \\
(17.9,18.3)\end{array}$ & $\begin{array}{l}4.15 \\
(4.04,4.15)\end{array}$ & $\begin{array}{l}15.4 \\
(14.9,15.4)\end{array}$ & $\begin{array}{l}8.90 \\
(8.43,8.95)\end{array}$ & $\begin{array}{l}0.118 \\
(0.070,0.118)\end{array}$ \\
\hline $3+3$ & $\mathrm{~T} 2$ & $\begin{array}{l}11.1 \\
(11.1,11.1)\end{array}$ & $\begin{array}{l}2.59 \\
(2.59,2.63)\end{array}$ & $\begin{array}{l}23.2 \\
(23.2,24.2)\end{array}$ & $\begin{array}{l}10.95 \\
(10.95,11.17)\end{array}$ & $\begin{array}{l}19.7 \\
(19.7,20.7)\end{array}$ & $\begin{array}{l}16.05 \\
(16.05,16.31)\end{array}$ & $\begin{array}{l}0.127 \\
(0.127,0.144)\end{array}$ \\
\hline STARPAC & T3 & $\begin{array}{l}13.2 \\
(13.0,13.7)\end{array}$ & $\begin{array}{l}2.74 \\
(2.68,2.90)\end{array}$ & $\begin{array}{l}17.1 \\
(17.1,17.4)\end{array}$ & $\begin{array}{l}3.86 \\
(3.82,4.11)\end{array}$ & $\begin{array}{l}13.9 \\
(13.9,14.8)\end{array}$ & $\begin{array}{l}7.87 \\
(7.87,8.38)\end{array}$ & $\begin{array}{l}0.468 \\
(0.441,0.506)\end{array}$ \\
\hline TITE-CRM & T3 & $\begin{array}{l}13.0 \\
(12.7,13.2)\end{array}$ & $\begin{array}{l}2.88 \\
(2.85,3.02)\end{array}$ & $\begin{array}{l}17.0 \\
(16.3,17.0)\end{array}$ & $\begin{array}{l}3.87 \\
(3.71,3.87)\end{array}$ & $\begin{array}{l}14.0 \\
(13.7,14.1)\end{array}$ & $\begin{array}{l}8.00 \\
(7.90,8.12)\end{array}$ & $\begin{array}{l}0.637 \\
(0.637,0.708)\end{array}$ \\
\hline $3+3$ & T3 & $\begin{array}{l}11.9 \\
(11.9,12.2)\end{array}$ & $\begin{array}{l}2.39 \\
(2.39,2.43)\end{array}$ & $\begin{array}{l}25.3 \\
(25.3,27.1)\end{array}$ & $\begin{array}{l}12.18 \\
(12.18,12.67)\end{array}$ & $\begin{array}{l}21.6 \\
(21.6,23.2)\end{array}$ & $\begin{array}{l}17.93 \\
(17.93,18.75)\end{array}$ & $\begin{array}{l}0.165 \\
(0.141,0.168)\end{array}$ \\
\hline STARPAC & T4 & $\begin{array}{l}15.0 \\
(14.7,15.6)\end{array}$ & $\begin{array}{l}2.23 \\
(2.16,2.37)\end{array}$ & $\begin{array}{l}19.5 \\
(19.4,19.7)\end{array}$ & $\begin{array}{l}4.60 \\
(4.58,4.64)\end{array}$ & $\begin{array}{l}15.8 \\
(15.8,16.8)\end{array}$ & $\begin{array}{l}8.90 \\
(8.90,9.69)\end{array}$ & $\begin{array}{l}0.728 \\
(0.691,0.776)\end{array}$ \\
\hline TITE-CRM & T4 & $\begin{array}{l}11.4 \\
(10.9,11.6)\end{array}$ & $\begin{array}{l}1.71 \\
(1.63,1.82)\end{array}$ & $\begin{array}{l}14.6 \\
(14.6,15.0)\end{array}$ & $\begin{array}{l}3.32 \\
(3.19,3.40)\end{array}$ & $\begin{array}{l}12.3 \\
(11.8,12.5)\end{array}$ & $\begin{array}{l}7.04 \\
(6.59,7.04)\end{array}$ & $\begin{array}{l}0.895 \\
(0.879,0.932)\end{array}$ \\
\hline $3+3$ & T4 & $\begin{array}{l}13.2 \\
(13.2,13.4)\end{array}$ & $\begin{array}{l}1.79 \\
(1.78,1.82)\end{array}$ & $\begin{array}{l}29.2 \\
(29.2,29.9)\end{array}$ & $\begin{array}{l}14.12 \\
(14.12,14.84)\end{array}$ & $\begin{array}{l}24.9 \\
(24.9,25.7)\end{array}$ & $\begin{array}{l}20.81 \\
(20.81,21.85)\end{array}$ & $\begin{array}{l}0.456 \\
(0.443,0.473)\end{array}$ \\
\hline STARPAC & T5 & $\begin{array}{l}12.8 \\
(12.7,13.3)\end{array}$ & $\begin{array}{l}3.59 \\
(3.54,3.81)\end{array}$ & $\begin{array}{l}16.5 \\
(16.4,17.0)\end{array}$ & $\begin{array}{l}3.74 \\
(3.74,3.88)\end{array}$ & $\begin{array}{l}13.7 \\
(13.6,14.2)\end{array}$ & $\begin{array}{l}7.41 \\
(7.41,8.08)\end{array}$ & $\begin{array}{l}0.444 \\
(0.439,0.476)\end{array}$ \\
\hline TITE-CRM & T5 & $\begin{array}{l}16.6 \\
(16.5,17.0)\end{array}$ & $\begin{array}{l}5.11 \\
(5.11,5.51)\end{array}$ & $\begin{array}{l}21.6 \\
(21.5,22.3)\end{array}$ & $\begin{array}{l}5.08 \\
(4.92,5.17)\end{array}$ & $\begin{array}{l}18.2 \\
(17.9,18.6)\end{array}$ & $\begin{array}{l}10.66 \\
(10.44,10.72)\end{array}$ & $\begin{array}{l}0.347 \\
(0.255,0.347)\end{array}$ \\
\hline $3+3$ & T5 & $\begin{array}{l}9.9 \\
(9.9,10.1)\end{array}$ & $\begin{array}{l}2.65 \\
(2.65,2.68)\end{array}$ & $\begin{array}{l}20.4 \\
(20.4,21.7)\end{array}$ & $\begin{array}{l}9.55 \\
(9.55,9.98)\end{array}$ & $\begin{array}{l}17.3 \\
(17.3,18.7)\end{array}$ & $\begin{array}{l}13.91 \\
(13.91,14.68)\end{array}$ & $\begin{array}{l}0.349 \\
(0.332,0.349)\end{array}$ \\
\hline
\end{tabular}

\section{Patients required and study length (economy)}

The ordering of designs in terms of the number of patients recruited is always the same as for the frequency of DLTs within the trial. On the other hand, the rulebased $3+3$ design most often is longest in study length, but requires least patients except for scenario T4 where it requires more patients than TITE-CRM (but fewer than STARPAC design). TITE-CRM requires more patients than STARPAC design for scenarios T1, T2 and $\mathrm{T} 5$, whereas STARPAC requires more for T4 (and there is little to choose between the designs for T3).

\section{Skipped patients (patient and investigator burden)}

For the numbers of skipped patients $3+3$ is uniformly (and substantially) worse than the other designs. STARPAC is best in scenarios T1, T2 and T5; whereas TITECRM is best for T4; and the two designs are very similar for T3. The order of designs in terms of the study duration is always the same as for patients skipped - the more patients are skipped the longer the trial.

\section{Discussion}

It has been noted that phase 1 trials often have a correct MTD estimation rate of only around $40 \%$ due to the low sample size [33]. We have described an alternative two stage dose-escalation (STARPAC) adaptive design [30] for phase 1 trials with delayed toxicity estimation (up to 28 days). We compare STARPAC design with TITE-CRM and $3+3$ designs via simulation with the $R$ programming language to illustrate the utility of simulation-based assessment under various plausible clinical scenarios, to enable evidenced based judgement dependent on key metrics which may relevant for the disease and patient population. An illustration of comparison is shown in Fig. 2. Our design compares favourably to other recently described modifications of TITE-CRM [34-37], such that recruitment is quicker and application of the design is easier. Furthermore, we have applied this design after rigorous simulations on to an actual oncology clinical trial, whilst others have yet to find real-life application.

Our simulations suggest that accuracy depends critically on the real toxicities of the doses studied, an 


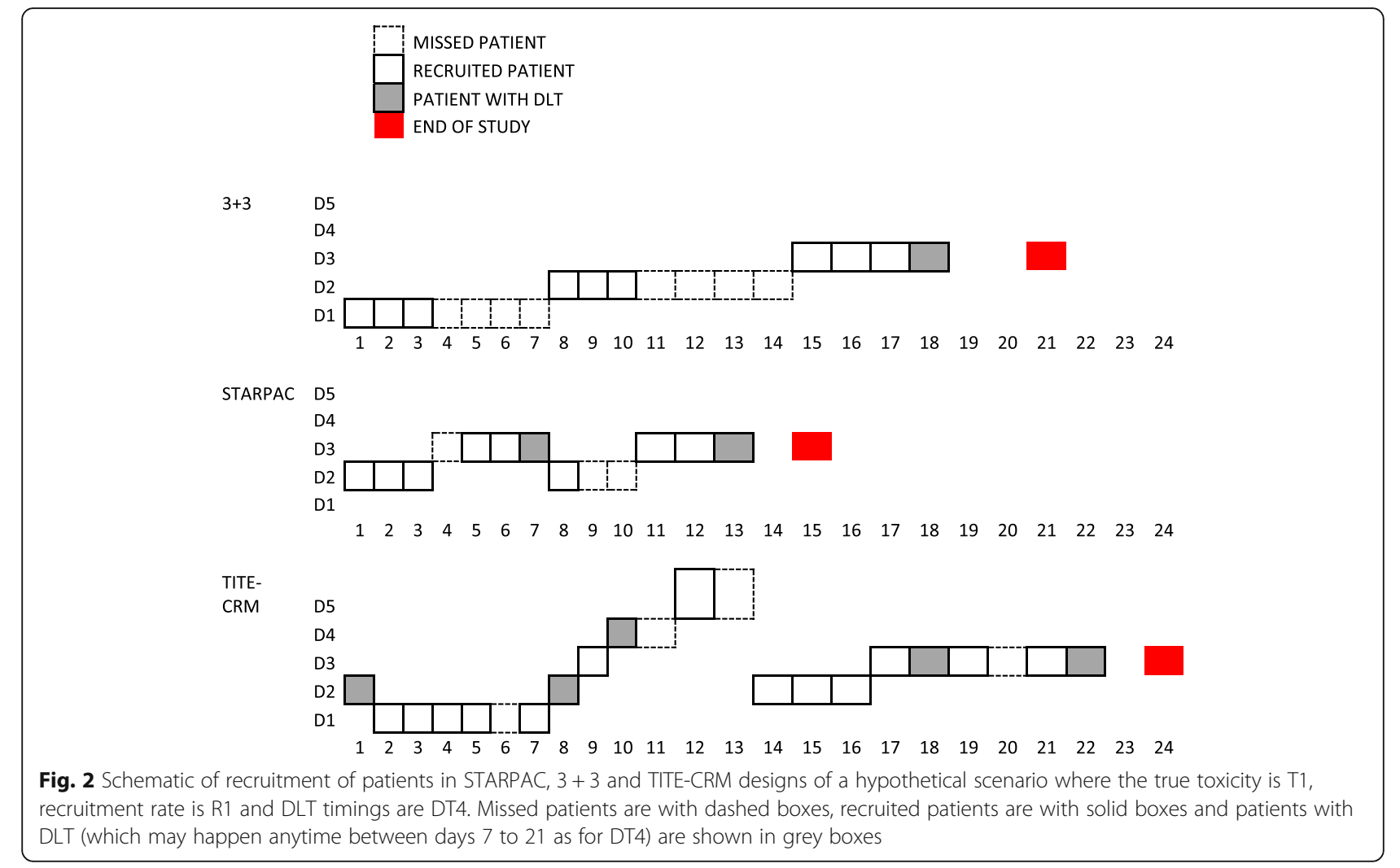

important clinical consideration. Nevertheless, we have seen that in our five scenarios it varied between just over $10 \%$ to just under $90 \%$, across the three design models and multiple scenarios that we have compared.

\section{Conclusions}

The STARPAC design has advantages and disadvantages compared to the alternative TITE-CRM method, and both methods appear superior to the traditional $3+3$ design particularly with regard to correct estimation of the MTD and duration of the trial. However, whenever the doses considered for the trial include ones with toxicity levels both above and below the target (TTL) of $30 \%$, the new STARPAC design outperforms both $3+3$ and TITE-CRM.

There are several reasons suggested for the high failure rate of confirmatory phase 3 trials. One reason may be a suboptimal treatment dose being selected for phase 2 and phase 3 trials. In our simulations the proposed STARPAC design is nearly always superior to $3+3$ in terms of the accuracy of MTD estimation and, in studies that include doses with toxicity levels above $30 \%$, it is superior to TITE-CRM as well.

We encourage clinical trialists to use simulations to provide evidence based adoption of different design models with particular reference to disease condition and patient population being studied.

\section{Additional files}

Additional file 1: STARPAC programming package: Code in $\mathrm{R}$ using a modified brcm package for STARPAC design. - Description of data: word document with Program code. (TXT $11 \mathrm{~kb}$ )

Additional file 2: Detailed STARPAC Tables: Detailed results of all simulations at all toxicity scenarios (T1-T5), rates of recruitment (R1-R2) and DLT timing scenarios (DT1-4) - Description of data: excel spreadsheet with multiple tabs. (DOCX $27 \mathrm{~kb}$ )

\section{Abbreviations}

13-cisRA: 13-cis retinoic acid; ATRA: All trans retinoic acid; CRM: Continual reassessment method; DLT: Dose limiting toxicities; DT: DLT timing; DTC: Dose-toxicity curve; MTD: Maximum tolerated dose; R: Rates of recruitment; RP2D: Recommended phase 2 dose; T: Toxicity; TITE-CRM: Timeto-event continual reassessment method; TTL: Target toxicity level

\section{Acknowledgements}

This paper is dedicated to the memory of Dr. Irene Kaimi, a statistician who was involved in an early draft of this paper but tragically died before it was completed. We thank the Barts and Brighton Centre for Experimental Cancer Medicine for help in setting up and conduction of the STARPAC trial.

\section{Authors' contributions}

BN performed simulations under guidance of PS. HMK provided clinical insight and experimental design. PS and HMK conceived the study. All. authors analysed results and co-wrote, read and approved the manuscript.

\section{Funding}

This work was supported by grants from Cancer Research UK (A16893, PS); Medical Research Council (MR/M015610/1, HMK). STARPAC clinical trial is supported by grants from Medical Research Council (MR/M015610/1, HMK) and Celgene Sarl (AX-CL-Panc-PI-003922, HMK). The funders had no role in 
the design of the study or collection, analysis, or interpretation of data or writing of the manuscript.

\section{Availability of data and materials}

Raw R program file is available as Additional file 1 for use by other researchers.

Summary raw data is available in Additional file 2.

\section{Ethics approval and consent to participate}

Not applicable for the data in this manuscript.

Ethical approval for STARPAC clinical trial; South Central - Berkshire Research Ethics Committee; 15/SC/0548 dated 13 October 2015.

\section{Consent for publication}

Not applicable.

\section{Competing interests}

HMK received funding for Investigator Initiated trial from Celgene Sarl (AXCL-Panc-PI-003922).

\section{Author details}

${ }^{1}$ Cancer Prevention Trials Unit, Wolfson Institute of Preventive Medicine, Queen Mary University of London, London, UK. ${ }^{2}$ Centre for Tumour Biology and Experimental Cancer Medicine, Barts Cancer Institute- a CRUK Centre of Excellence, Queen Mary University London, London EC1M 6BQ, UK. ${ }^{3}$ Current addresses: Exploristics Ltd, Belfast, UK. ${ }^{4}$ Current addresses: School of Cancer \& Pharmaceutical Sciences, and King's Clinical Trials Unit, King's College London, London, UK.

\section{Received: 16 December 2018 Accepted: 6 June 2019} Published online: 26 June 2019

\section{References}

1. Dixon WJ, Mood AM. A method for obtaining and analyzing sensitivity data. J Am Stat Assoc. 1948;43(241):109-26.

2. Storer BE. Design and analysis of phase I clinical trials. Biometrics. 1989;45(3): 925-37.

3. O'Quigley J: Continual Reassessment and Related Dose-Finding Designs. Statistical science: a review journal of the Institute of Mathematical Statistics 2010;25(2):202-216 doi:https://doi.org/10.1214/10-STS332, 25(2):202-216.

4. Goodman SN, Zahurak ML, Piantadosi S. Some practical improvements in the continual reassessment method for phase I studies. Stat Med. 1995; 14(11):1149-61.

5. Babb J, Rogatko A, Zacks S. Cancer phase I clinical trials: efficient dose escalation with overdose control. Stat Med. 1998;17(10):1103-20.

6. lasonos A, O'Quigley J. Interplay of priors and skeletons in two-stage continual reassessment method. Stat Med. 2012;31(30):4321-36 doi: 4310. 1002/sim.5559. Epub 2012 Aug 4315.

7. O'Quigley J, Shen LZ. Continual reassessment method: a likelihood approach. Biometrics. 1996;52(2):673-84.

8. lasonos A. A comprehensive comparison of the continual reassessment method to the standard $3+3$ dose escalation scheme in phase I dosefinding studies. Clin Trials. 2008:5(5):465-77.

9. Reiner E, Paoletti X, O'Quigley J. Operating characteristics of the standard phase I clinical trial design. Comput Stat Data Anal. 1999;30(3):303-15.

10. Council MR: "A quick guide why not to use a+B designs" adaptive designs working group of the MRC network of hubs for Trials Methodology Research 2016.

11. Simon R, Freidlin B, Rubinstein L, Arbuck SG, Collins J, Christian MC Accelerated titration designs for phase I clinical trials in oncology. J Natl Cancer Inst. 1997:89(15):1138-47.

12. Skolnik JM, Barrett JS, Jayaraman B, Patel D, Adamson PC. Shortening the timeline of pediatric phase I trials: the rolling six design. J Clin Oncol. 2008, 26(2):190-5.

13. Cheung YK, Chappell R. Sequential designs for phase I clinical trials with late-onset toxicities. Biometrics. 2000;56(4):1177-82.

14. Normolle D, Lawrence T. Designing dose-escalation trials with late-onset toxicities using the time-to-event continual reassessment method. J Clin Oncol. 2006;24(27):4426-33.
15. Froeling FE, Kocher HM. Homeostatic restoration of desmoplastic stroma rather than its ablation slows pancreatic cancer progression. Gastroenterology. 2015;148(4):849-50.

16. Ene-Obong A, Clear AJ, Watt J, Wang J, Fatah R, Riches JC, Marshall JF, ChinAleong J, Chelala C, Gribben JG, et al. Activated pancreatic stellate cells sequester CD8+ T cells to reduce their infiltration of the juxtatumoral compartment of pancreatic ductal adenocarcinoma. Gastroenterology. 2013;145(5):1121-32.

17. Froeling FE, Feig C, Chelala C, Dobson R, Mein CE, Tuveson DA, Clevers H, Hart IR, Kocher HM. Retinoic acid-induced pancreatic stellate cell quiescence reduces paracrine Wnt-beta-catenin signaling to slow tumor progression. Gastroenterology. 2011;141(4):1486-97.

18. Von Hoff DD, Ervin T, Arena FP, Chiorean EG, Infante J, Moore M, Seay T, Tjulandin SA, Ma WW, Saleh MN, et al. Increased survival in pancreatic cancer with nab-paclitaxel plus gemcitabine. N Engl J Med. 2013;369(18): 1691-703.

19. Arrieta O, Gonzalez-De la Rosa CH, Arechaga-Ocampo E, VillanuevaRodriguez G, Ceron-Lizarraga TL, Martinez-Barrera L, Vazquez-Manriquez ME, Rios-Trejo MA, Alvarez-Avitia MA, Hernandez-Pedro N, et al. Randomized phase II trial of all-trans-retinoic acid with chemotherapy based on paclitaxel and cisplatin as first-line treatment in patients with advanced non-small-cell lung cancer. J Clin Oncol. 2010;28(21):3463-71.

20. Budd GT, Adamson PC, Gupta M, Homayoun P, Sandstrom SK, Murphy RF, McLain D, Tuason L, Peereboom D, Bukowski RM, et al. Phase I/II trial of alltrans retinoic acid and tamoxifen in patients with advanced breast cancer. Clin Cancer Res. 1998;4(3):635-42.

21. Chen GQ, Shen ZX, Wu F, Han JY, Miao JM, Zhong HJ, Li XS, Zhao JQ, Zhu J, Fang ZW, et al. Pharmacokinetics and efficacy of low-dose all-trans retinoic acid in the treatment of acute promyelocytic leukemia. Leukemia. 1996; 10(5):825-8

22. Conley BA, Egorin MJ, Sridhara R, Finley R, Hemady R, Wu S, Tait NS, Van Echo DA. Phase I clinical trial of all-trans-retinoic acid with correlation of its pharmacokinetics and pharmacodynamics. Cancer Chemother Pharmacol. 1997;39(4):291-9.

23. Moore DF Jr, Pazdur R, Sugarman S, Jones D 3rd, Lippman SM, Bready B, Abbruzzese JL. Pilot phase II trial of 13-cis-retinoic acid and interferon-alpha combination therapy for advanced pancreatic adenocarcinoma. Am J Clin Oncol. 1995;18(6):525-7.

24. Brembeck FH, Schoppmeyer K, Leupold U, Gornistu C, Keim V, Mossner J, Riecken EO, Rosewicz S. A phase II pilot trial of 13-cis retinoic acid and interferon-alpha in patients with advanced pancreatic carcinoma. Cancer. 1998:83(11):2317-23.

25. Michael A, Hill M, Maraveyas A, Dalgleish A, Lofts F. 13-cis-retinoic acid in combination with gemcitabine in the treatment of locally advanced and metastatic pancreatic cancer--report of a pilot phase II study. Clin Oncol (R Coll Radiol). 2007:19(2):150-3.

26. Von Hoff DD, Ramanathan RK, Borad MJ, Laheru DA, Smith LS, Wood TE, Korn RL, Desai N, Trieu V, Iglesias JL, et al. Gemcitabine plus nab-paclitaxel is an active regimen in patients with advanced pancreatic cancer: a phase I/II trial. J Clin Oncol. 2011;29(34):4548-54.

27. Iasonos A, O'Quigley J. Interplay of priors and skeletons in two-stage continual reassessment method. Stat Med. 2012;31(30):4321-36.

28. Sweeting M, Mander A, Sabin T: bcrm: Bayesian continual reassessment method designs for phase I dose-finding trials. 2013 54(13):26.

29. Neuenschwander B, Branson M, Gsponer T. Critical aspects of the Bayesian approach to phase I cancer trials. Stat Med. 2008;27(13):2420-39.

30. lasonos A, O'Quigley J. Adaptive dose-finding studies: a review of modelguided phase I clinical trials. J Clin Oncol. 2014;32(23):2505-11.

31. R Core Team (2014). R: A language and environment for statistical computing. R Foundation for Statistical Computing, Vienna, Austria. http:// www.R-project.org/.

32. Cheung YK: Dfcrm: dose-finding by the continual reassessment method. $R$ package version 0.2-2. 2013.

33. lasonos A, Gonen M, Bosl GJ. Scientific review of phase I protocols with novel dose-escalation designs: how much information is needed? J Clin Oncol. 2015;33(19):2221-5.

34. Fu H, Manner D. Bayesian adaptive dose-finding studies with delayed responses. J Biopharm Stat. 2010;20(5):1055-70. https://doi.org/10.1080/ 10543400903315740

35. Lin R, Yin G: Nonparametric overdose control with late-onset toxicity in phase I clinical trials. Biostatistics 2017, 18(1):180-194. doi: https://doi.org/10. 1093/biostatistics/kxw1038. Epub 2016 Aug 1022. 
36. Lin R, Yuan Y. Time-to-event model-assisted designs for dose-finding trials with delayed toxicity. Biostatistics. 2019(5460289):15.

37. Yin $\mathrm{G}$, Zheng $\mathrm{S}$, Xu J. Fractional dose-finding methods with late-onset toxicity in phase I clinical trials. J Biopharm Stat. 2013;23(4):856-70. https:// doi.org/10.1080/10543406.10542013.10789892.

\section{Publisher's Note}

Springer Nature remains neutral with regard to jurisdictional claims in published maps and institutional affiliations.

Ready to submit your research? Choose BMC and benefit from:

- fast, convenient online submission

- thorough peer review by experienced researchers in your field

- rapid publication on acceptance

- support for research data, including large and complex data types

- gold Open Access which fosters wider collaboration and increased citations

- maximum visibility for your research: over $100 \mathrm{M}$ website views per year

At $\mathrm{BMC}$, research is always in progress. 